\begin{tabular}{|l|l|l||}
\hline \multicolumn{2}{|c|}{ PublisherInfo } \\
\hline \hline PublisherName & $:$ & BioMed Central \\
\hline \hline PublisherLocation & $:$ & London \\
\hline \hline PublisherImprintName & $:$ & BioMed Central \\
\hline \hline
\end{tabular}

\title{
A role for PDGF in breast tumor desmoplasia
}

\begin{tabular}{|l|l|l||}
\hline \multicolumn{2}{|c|}{ ArticleInfo } \\
\hline \hline ArticleID & $:$ & 3737 \\
\hline \hline ArticleDOI & $:$ & $10.1186 /$ bcr-2000-66700 \\
\hline \hline ArticleCitationID & $:$ & 66700 \\
\hline \hline ArticleSequenceNumber & $:$ & 103 \\
\hline \hline ArticleCategory & $:$ & Paper Report \\
\hline ArticleFirstPage & $:$ & 1 \\
\hline \hline ArticleLastPage & $:$ & 4 \\
\hline \hline & & RegistrationDate : 2000-10-2 \\
\hline ArticleHistory & $:$ & OnlineDate \\
\hline \hline ArticleCopyright & $:$ & Current Science Ltd2000-10-2 \\
\hline \hline ArticleGrants & $:$ & \\
\hline \hline ArticleContext & $:$ & 1305822 \\
\hline \hline
\end{tabular}


Aff1 Lawrence Berkeley National Laboratory, Berkeley, USA

\section{Keywords}

Breast carcinoma, C-ras, desmoplasia, dominant-negative mutants, paracrine growth factors, PDGF

\section{Introduction}

Desmoplastic response refers to the phenomenon that occurs in many solid tumors, including breast carcinomas, where stromal myofibroblasts synthesize and deposit abundant collagenous material, ultimately forming a palpable lump. Several mechanistic models have been proposed to account for this desmoplastic response including cytokine, blood and tissue coagulation and paracrine growth factor mechanisms. Due to the lack of tractable and reproducible model systems for studying the desmoplastic response, compelling evidence in support of any of these models has not emerged.

\section{Aims}

To develop a cellular model of the desmoplastic response and to test whether the desmoplastic response can be attributed to alterations in autocrine and/or paracrine growth factor production in the carcinoma cells themselves and, if so, to identify the molecules involved.

\section{Comments}

This paper provides an important demonstration of the exquisite and dynamic interplay that exists between the breast epithelial cell (or tumor cell) and its microenvironment to regulate cellular phenotypes. The authors have successfully reproduced the desmoplastic response in the context of a xenograft model, thereby enabling a molecular dissection of contributing cellular pathways. Their studies have implicated platelet derived growth factor (PDGF) as a tumor-generated paracrine factor that is an important determinant of the desmoplastic response. It is important, however, to recognize that the evidence supporting this conclusion is derived from a single model using a specific cellular starting material and thus may not be representative of all human breast tumor desmoplasia. Moreover, important differences between mouse and human breast tissue organization that may be of critical 
importance to the mechanism of the desmoplastic response have not been considered here. Given the limitations of the model, the title of the paper, while quite provocative, may represent an oversimplification of the role of PDGF in the desmoplastic response. Rather, it seems more appropriate to recognize that PDGF may be one of several components required for initiation of the desmoplastic response in humans.

\section{Methods}

C-ras transfected MCF-7 cell lines, W7 and W9, or a control transfected cell clone, neo MCF-7, were injected into the mammary fat pads of ovariectomized nude mice. Tumor formation and the desmoplastic response were monitored in the absence and presence of estrogen. Conditioned medium from cells showing a positive estrogen-independent desmoplastic response was assayed for myofibroblast mitogenic activity. A dominant negative PDGF-A mutant gene was transfected into response-positive cells and the resulting cells were injected into nude mice to determine the extent of their desmoplastic response.

\section{Results}

In the presence of estrogen, W7 and W9 cell lines gave rise to substantial cellular tumors that were devoid of a tumor stroma. In the absence of estrogen, the W9 cell line gave rise to tumors exhibiting a dramatic desmoplastic response. Conditioned medium derived from the W9 cells gave rise to a dramatic myofibroblast mitogenic response in vitro. Fractionation of this conditioned medium showed that the peak of mitogenic activity contained PDGF. In order to determine whether the production of PDGF is required to stimulate the desmoplastic response, W9 cells were transfected with a dominant negative PDGF-A gene. In these transfected cells all three forms of PDGF were significantly down-modulated whereas other growth factors (TGF $\alpha$, TGF $\beta$, IGF-1 and IGF-II) were not. When injected into nude mice, these PDGF-reduced cells were still tumorigenic in the absence of estrogen, but unlike the parental W9 cells, these cells failed to exhibit a desmoplastic response.

\section{Discussion}

The results presented here suggest that the desmoplastic response is dependent upon a constitutive paracrine growth factor mechanism rather than an immune-mediated response. The data indicate that the desmoplastic response is acutely sensitive to the levels of autocrine and paracrine growth factors in the tumor microenvironment and that, at least in this model, the tumor-secreted factor, PDGF, is a key player. These data predict that the desmoplastic response would be favored in situations where tumor cells produce paracrine growth factors at levels that promote cell growth in the stromal compartment 
rather than growth of the actual tumor cells. Tumor cells that respond to PDGF stimuli or have inherently high growth rates due to other factors would be dominant over the slower-growing myofibroblast components and thus result in the production of cellular, rather than stromal, tumors. This interpretation is supported by the demonstration that W9 cells, while exhibiting a desmoplastic response in the absence of estrogen, form aggressive cellular tumors when grown in the presence of growthpromoting estrogen stimuli.

\section{References}

1. Shao Z-M, Nguyen M, Barsky SH: Human breast carcinoma desmoplasia is PDGF initiated. Oncogene. 2000, 19: 4337-4345. 